\title{
Variability in Glucosinolate Content among Camelina Species
}

\section{Roberto Russo, Incoronata Galasso, Remo Reggiani*}

Istituto di Biologia e Biotecnologia Agraria, CNR, Milano, Italy.

Email: ${ }^{*}$ reggiani@ibba.cnr.it

Received September $30^{\text {th }}$, 2013; revised December $23^{\text {rd }}$, 2013; accepted January $17^{\text {th }}, 2014$

Copyright (C) 2014 Roberto Russo et al. This is an open access article distributed under the Creative Commons Attribution License, which permits unrestricted use, distribution, and reproduction in any medium, provided the original work is properly cited. In accordance of the Creative Commons Attribution License all Copyrights (c) 2014 are reserved for SCIRP and the owner of the intellectual property Roberto Russo et al. All Copyright (C) 2014 are guarded by law and by SCIRP as a guardian.

\section{ABSTRACT}

Glucosinolate content in Camelina sativa (L.) Crantz (false flax, gold-of-pleasure) and its relatives C. microcarpa, $C$. alyssum, $C$. rumelica and $C$. hispida was investigated. With the exception of $C$. hispida in which GSL3 was absent, in all remaining species, three characteristic glucosinolates (GSL1, GSL2 and GSL3) were identified. Camelina genotypes of spring type (C. sativa CAM134, C. alyssum CAM21) showed a typical pattern of glucosenolates with GSL1 > GSL3. GSL1 was present in traces in C. microcarpa and at low levels in $C$. rumelica and $C$. alyssum subsp. alyssum. In $C$. hispida, the GSL1 content was greater than GSL2 and, only in this specie, GSL2 represented less than $\mathbf{5 0 \%}$ of total glucosinolates. These differences in the glucosinolate pattern among Camelina species could be exploited to reduce the total content of glucosinolates in $C$. sativa.

\section{KEYWORDS}

\section{Camelina Species; Glucosinolate; Flour; Winter and Spring Type; Oilseed Crop}

\section{Introduction}

Glucosinolates (GSLs) are a class of substances present in plants of the Brassicaceae family [1]. Chemically, they are $\beta$-thioglucoside $\mathrm{N}$-hydroxysulfates with a side chain and sulfur linked $\beta$-D-glucopyranose. GSLs are anionic and sulfur-rich compounds that after hydrolysis by the enzyme thioglucosidase (called myrosinase) produce different catabolites (e.g., isothiocyanates, thiocyanates, epithionitriles and nitriles) with detrimental and antinutritional characteristics. These molecules derived from GSLs are responsible for their toxicity as impairment of thyroid, growth, fertility, irritation of the gastro-intestinal mucosa [2].

Recently, some species of the Brassicaceae family (Brassica napus, Camelina sativa, Brassica carinata, etc.) have become attractive for the exploitation of seed oil as fuel [3]. The extraction of oil from seeds makes available protein-enriched flours as an ingredient in animal feed. However, exploitation of these flours may be limited by the presence of GSLs. In the case of Brassica napus were

\footnotetext{
${ }^{*}$ Corresponding author.
}

selected varieties with a low content of GSLs and, consequently, canola meal is commonly used in animal diets [4].

Difference is the case of Camelina sativa where less efforts in research on its GSLs were made and genotypes low in GSLs have yet to be identified and/or selected. For this reason, the American food and Drug Administration has limited the inclusion of camelina meal in feedlot beef cattle rations to $10 \%$ [5].

In camelina, three main GSLs were identified named GSL1 (9-methyl-sulfinyl-nonyl-GSL), GSL2 (10-methylsulfinyl-decyl-GSL) and GSL3 (11-methyl-sulfinyl-undecyl-GSL (Figure 1) [6]. GSL1, besides being present in camelina, is also present in Arabis alpine, Arabis amplexicaulis, Arabis turrita, Biscutella auriculata, Capsella bursapastoris, Rorippa globosa, while GSL2 was detected only in Arabis alpine and Capsella bursapastoris [7]. GSL3 is typical of Camelina species instead [7]. Schuster and Friedt (1998) reported a high variability among camelina genotypes in total GSLs on a dry matter (DM) basis (from 13.2 to $36.2 \mathrm{mmol} \cdot \mathrm{kg}^{-1}$ ) and in the relative abundance of GSL1 and GSL3 [6]. In a previous 


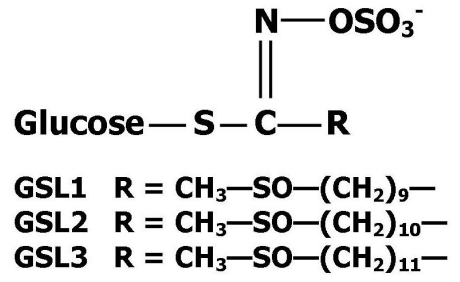

Figure 1. Chemical structure of camelina GSLs.

study, different patterns of GSLs based on the relative content of GSL1 and GSL3 were identified among $\mathrm{Ca}$ melina sativa genotypes [8]. In particular, C. sativa variety Calena (accession number CAM134) showed opposite levels of GSL1 and GSL3 with respect to C. sativa accession Ames 28372 or PI650168. In the present study, we extended the investigation on the GSL levels among Camelina species. The characterization quali-quantitative of GSLs in these species may be important for a future camelina breeding.

\section{Materials and Methods}

Seeds of Camelina sativa (L.) Crantz, Camelina microcarpa Andrz. ex DC., Camelina alyssum (Mill.) Thell., Camelina rumelica Velen and Camelina hispida var. grandiflora (Boiss.) Hedge, were kindly provided by the Institute of Plant Genetics and Crop Plant Research (IPK, http://gbis.ipk-gatersleben.de/ and they were identified by the accession number CAM), Germany and the United Stated Department of Agricultural (USDA, http://www.ars-grin.gov/npgs/acc/acc queries.html, identified by the accession number PI or Ames), USA (Table 1). In order to define their life form (i.e. winter or spring type) all species were sown in the end of winter (March 10, 2009) and in the beginning of autumn (October 1, 2009) in small plots in an open field.

GSLs were extracted according to Russo and Reggiani [8]. Camelina seeds were defatted with hexane and GSLs extracted with $70 \%$ hot ethanol for $3 \mathrm{~h}$. The sample were centrifuged for $15 \mathrm{~min}$ at $15,000 \mathrm{rpm}$ ). Five hundred $\mu \mathrm{L}$ of ethanol extract were adsorbed onto a small DEAESephadex A-25 column in formate form (100 mg). The column was then washed twice with $1 \mathrm{~mL}$ of $20 \mathrm{mM}$ sodium acetate at $\mathrm{pH}$ 4.0. Desulfation of GSLs was obtained by $50 \mu \mathrm{L}$ of sulfatase $(500 \mathrm{U})$ at $37^{\circ} \mathrm{C}$ overnight. Desulfo-GSLs were eluted from the column with $1.5 \mathrm{~mL}$ of water and dried at $65^{\circ} \mathrm{C}$. The samples were resuspended in ethanol before HPLC analysis.

Desulfo-GSLs were separated by gradient HPLC and detection at $229 \mathrm{~nm}$. A $250 \times 4.6 \mathrm{~mm}$ Phenomenex Kinetex C18 $(2.6 \mu \mathrm{m})$ was used for separation. The mobile phase consisted of two eluents: A) water (HPLC-grade); $\mathrm{B})$ acetonitrile. The flow rate was $1.0 \mathrm{~mL} \cdot \mathrm{min}^{-1}$. The program started with $98 \% \mathrm{~A}$ and $2 \% \mathrm{~B}$ for 2 min followed by a linear gradient over $15 \mathrm{~min}$ to $60 \% \mathrm{~A}$ and $40 \% \mathrm{~B}$.
Table 1. List of Camelina species used in this study with their accession number, donor and country of origin.

\begin{tabular}{|c|c|c|c|c|}
\hline Camelina species & $\begin{array}{c}\text { Accession } \\
\text { number }\end{array}$ & Origin & Donor & Life form \\
\hline C. sativa & CAM134 & Austria & IPK $^{*}$ & Spring type \\
\hline C. sativa & $\begin{array}{c}\text { PI650168 } \\
\text { Ames } 28372\end{array}$ & USA & $\mathrm{USDA}^{ \pm}$ & Winter type \\
\hline C. microcarpa & $\begin{array}{c}\text { PI633186 } \\
\text { Ames21213 }\end{array}$ & Hungary & USDA & Winter type \\
\hline C. microcarpa & $\begin{array}{c}\text { PI633188 } \\
\text { Ames22572 }\end{array}$ & Poland & USDA & Winter type \\
\hline C. microcarpa & CAM47 & Germany & IPK & Winter type \\
\hline $\begin{array}{l}\text { C. alyssum subsp. } \\
\text { alyssum }\end{array}$ & CAM176 & unknown & IPK & Winter type \\
\hline C. alyssum & CAM21 & Germany & IPK & Spring type \\
\hline C. rumelica & $\begin{array}{c}\text { PI650138 } \\
\text { Ames21327 }\end{array}$ & Iran & USDA & Winter type \\
\hline C. rumelica & CAM244 & Russia & IPK & Winter type \\
\hline $\begin{array}{l}\text { C. hispida var. } \\
\text { grandiflora }\end{array}$ & $\begin{array}{c}\text { PI650133 } \\
\text { Ames21324 }\end{array}$ & Turkey & USDA & Winter type \\
\hline
\end{tabular}

"IPK Leibniz Institute of Plant Genetics and Crop Plant Research, Gatersleben, Germany, http://gbis.ipkgatersleben.de/; ${ }^{ \pm}$USDA United States Department of Agriculture, USA,

http://www.ars-grin.gov/npgs/acc/acc_queries.html.

Then in 5 min to $100 \%$ B, followed by $100 \%$ B for 5 min. The program returned to $98 \% \mathrm{~A}$ and $2 \% \mathrm{~B}$ by a linear gradient of 1 min followed by at least 10 min equilibration.

\section{Results and Discussion}

Among all Camelina species sown in spring only $C$. sativa CAM 134 and C. alyssum CAM 21 resulted to be spring type (without vernalization requirement) because they started the stem elongation after about 50 days, all the remaining samples resulted winter type since required vernalisation to attain stem elongation and subsequent flowering. In order to collect seeds from plants grown in the same climatic condition, all species were sown in autumn and only the seeds obtained from the winter sowing were harvested in June 2010 and used for GSL content analysis.

GSLs from different Camelina species were separated by HPLC and quantified in order to determine the GSL pattern (Figure 2, Table 2). In the case of C. hispida (PI650133) only one genotype was possible to analyse because only one accession of this species was present in both genbanks (IPK and USDA). Therefore, only in this case, three independent analyses were carried out using meals obtained from seeds collected from three single plants (named a, b and c) while for the other species two or three genotypes were analysed (Table 1 ).

Figure 2 shows different GSL separations among Camelina species analyzed. In C. sativa CAM134, the content of GSL1 was greater than GSL3 (Figure 2(a)) 


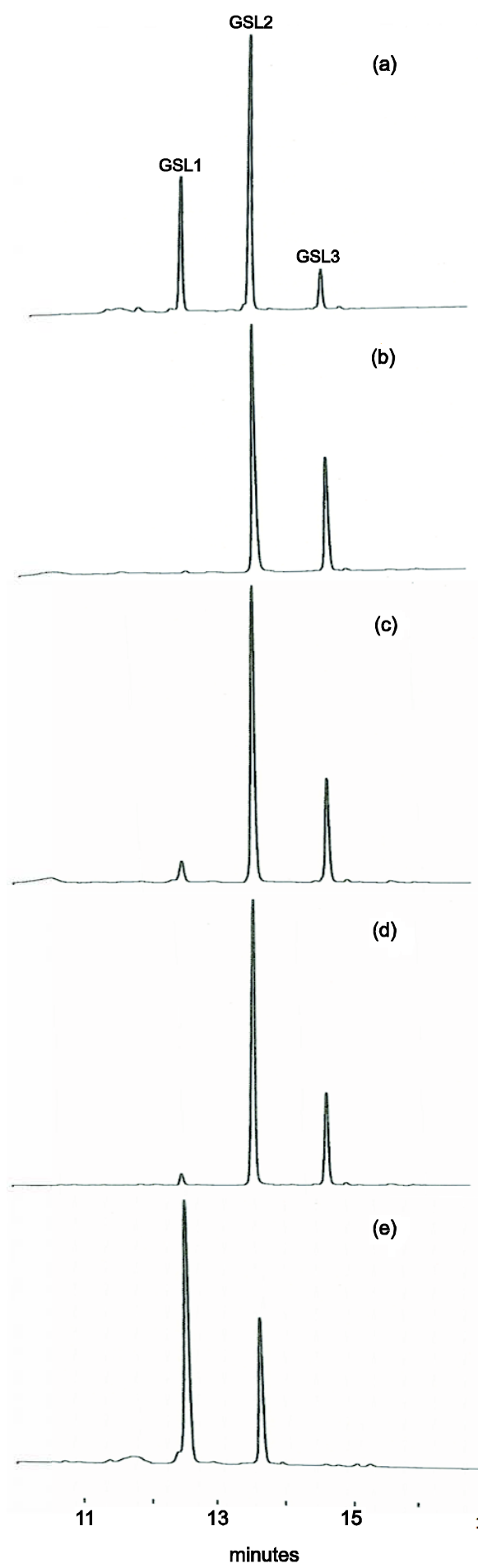

Figure 2. Chromatogramme of GSLs from different $\mathrm{Ca}$ melina species. (a) C. sativa CAM 134; (b) C. microcarpa PI 650186; (c) C. alyssum CAM 176; (d) C. rumelica PI 650138; (e) C. hispida PI 650133b.

and a similar distribution was also observed in C. alyssum CAM21 (Table 2). This pattern was already described in six genotypes of C. sativa [7] and may be associated with spring type Camelina genotypes (Table 1).
Table 2. GSLs content in different Camelina species.

\begin{tabular}{ccccc}
\hline $\begin{array}{c}\text { Camelina } \\
\text { accession }\end{array}$ & GSL1 & GSL2 & GSL3 & $\begin{array}{c}\text { Total } \\
\text { GSLs }\end{array}$ \\
\hline CAM134 & $6.12 \pm 0.09$ & $11.6 \pm 0.36$ & $1.76 \pm 0.05$ & 19.5 \\
PI650168 & $1.14 \pm 0.04$ & $10.1 \pm 0.26$ & $3.76 \pm 0.12$ & 15.0 \\
PI633186 & $0.09 \pm 0.01$ & $12.6 \pm 0.22$ & $5.31 \pm 0.07$ & 18.0 \\
PI633188 & $0.18 \pm 0.01$ & $9.71 \pm 0.31$ & $7.70 \pm 0.24$ & 17.6 \\
CAM47 & $0.19 \pm 0.01$ & $11.5 \pm 0.36$ & $5.25 \pm 0.17$ & 17.0 \\
CAM176 & $0.78 \pm 0.03$ & $11.0 \pm 0.39$ & $3.74 \pm 0.27$ & 15.6 \\
CAM21 & $5.62 \pm 0.25$ & $13.2 \pm 0.61$ & $1.68 \pm 0.32$ & 20.5 \\
PI650138 & $0.58 \pm 0.02$ & $14.0 \pm 0.45$ & $4.84 \pm 0.16$ & 19.4 \\
CAM244 & $0.65 \pm 0.02$ & $15.7 \pm 0.49$ & $4.44 \pm 0.14$ & 20.8 \\
PI650133 (a) & $12.5 \pm 0.27$ & $9.29 \pm 0.14$ & nd & 21.8 \\
PI650133 (b) & $8.75 \pm 0.22$ & $4.88 \pm 0.12$ & nd & 13.6 \\
PI650133 (c) & $8.08 \pm 0.26$ & $6.67 \pm 0.21$ & nd & 14.8 \\
\hline
\end{tabular}

*nd, not detected; data are expressed as $\mathrm{mmol} \cdot \mathrm{Kg}^{-1} \mathrm{DM}$.

In CAM134 and CAM21, GSL1 represented 31\% and 27\% on total GSLs (Figure 3), respectively, and was more than three times the content of GSL3 (Table 2). The total GSLs content in these spring genotypes was about 20 $\mathrm{mmol} \cdot \mathrm{kg}^{-1} \mathrm{DM}$.

In C. microcarpa (PI633186, PI633188 and CAM47), the content of GSL1 was extremely low (Figure 2(b), Table 2) and represented about 1\% of total GSLs (Figure 3). The total GSL content in the three C. microcarpa genotypes was similar (17 - $18 \mathrm{mmol} \cdot \mathrm{kg}^{-1} \mathrm{DM}$; Table 2). However, GSL3 resulted more abundant in PI633188 (44\%) than in the other C. microcarpa genotypes (Figure 3).

In C. sativa PI650168, C. rumelica genotypes (PI650138 and CAM244) and C. alyssum CAM176, the concentration in samples of GSL1 was low even if higher than in C. microcarpa (Figures 2(c)-(d); Table 2). Schuster and Friedt [6] associated this GSL pattern to winter type genotypes or wild Camelina species. In these genotypes, GSL1 represented 3\% - 7\% and GSL3 21\% - 25\% on total GSLs, respectively (Figure 3). The level of total GSLs was higher in PI650138 and CAM244 (C. rumelica) than in PI650168 and CAM176 (Table 2).

C. hispida plants (PI650133a-c) exhibited a GSL pattern very different from the other Camelina species (Figure 2(e), Figure 3). In these plants, GSL3 was undetectable and GSL1 was the predominant GSL, being $55 \%$ - 64\% on total GSLs (Table 2, Figure 3). The presence of GSL1 and GSL2 and the absence of GSL3 was already observed in Arabis alpine and Capsella bursapastoris but in these two last species also other GSLs were detected [7]. In two plants of PI650133 (b and c), the content of total GSLs was low (13.6 and 14.8 $\mathrm{mmol} \cdot \mathrm{kg}^{-1} \mathrm{DM}$, Table 2) and, among the various Camelina species, showed the lowest levels of GSL2 


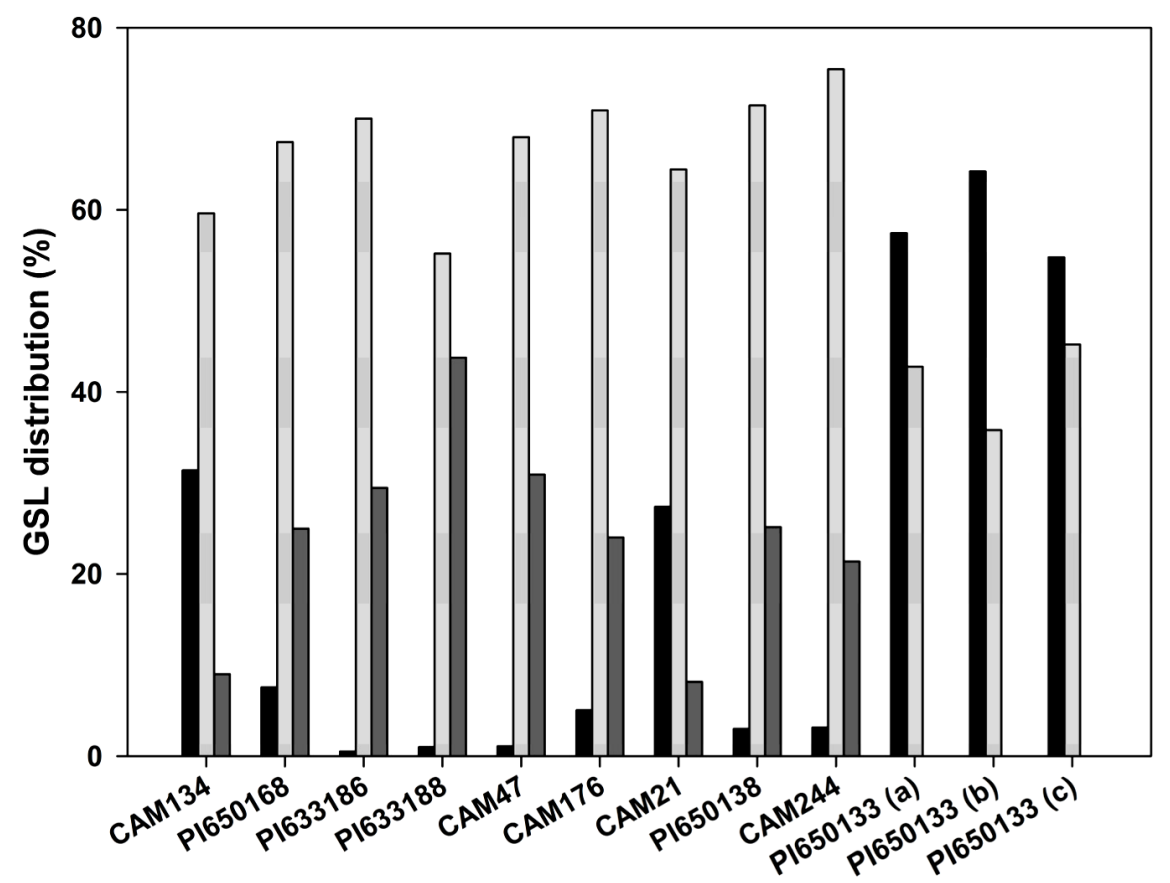

Figure 3. Distribution (\%) of GSL1 (black bar), GSL2 (light gray bar) and GSL3 (dark gray bar) on total GSL content in Camelina species.

(4.88 and $6.67 \mathrm{mmol} \cdot \mathrm{kg}^{-1} \mathrm{DM}$, respectively).

\section{Conclusions}

Camelina sativa is a promising oilseed crop for the production of biofuels. The use of the remaining cake from oil extraction, however, is a critical factor to further increase the economical value of the plant. The use of camelina flour is currently limited both in Europe and USA by the content of GSLs.

In the present study, we showed that in the genus $\mathrm{Ca}$ Melina presents a great variability in the levels of the three GSLs. In particular, low levels of GSL1 were observed in C. microcarpa, C. rumelica and C. alyssum subsp. alyssum while GSL3 was even absent in C. hispida. Instead, GSL2 was low in some plants of $C$. hispida.

Recently, it has been demonstrated that hybridizations among $C$. sativa and other Camelina species (C. microcarpa, C. alyssum and C. rumelica) are possible [9]. This opens the way to reduce the content of GSLs by classical plant breeding or molecular techniques. However, since the content of GSLs in camelina flours was seen inversely related to the content of sinapina [8], even this anti-nutritional factor must be simultaneously monitored.

\section{Acknowledgements}

This work was supported by Regione Lombardia, agreement Regione/CNR, project 2 "Risorse biologiche e tecnologie innovative per lo sviluppo sostenibile del sistema agro-alimentare”.

\section{REFERENCES}

[1] J. W. Fahey, A. T. Zalcmann and P. Talalay, "The Chemical Diversity and Distribution of Glucosinolates and Isothiocyanates among Plants," Phytochemistry, Vol. 56, No. 1, 2001, pp. 5-51.

http://dx.doi.org/10.1016/S0031-9422(00)00316-2

[2] European Food Safety Authority, "Glucosinolates as Undesirable Substances in Animal Feed," EFSA Journal, Vol. 590, No. 1, 2008, pp. 1-76.

[3] S. I. Warwick, "Brassicaceae in Agriculture," In: R. Schmidt and I. Bancroft, Eds., Genetics and Genomics of the Brassicaceae. Plant Genetics and Genomics: Crops and Models, Springer, New York, 2011, pp. 33-65. http://dx.doi.org/10.1007/978-1-4419-7118-0_2

[4] J. M. Bell, "Factors Affecting the Nutritional Value of Canola Meal: A Review," Canadian Journal of Animal Science, Vol. 73, No. 4, 1993, pp. 689-697. http://pubs.aic.ca/doi/pdf/10.4141/cjas93-075 http://dx.doi.org/10.4141/cjas93-075

[5] S. R. Schill, "Camelina Meal Approved for Feedlot Cattle,” Biodiesel Magazine, 2010. http://www.biodieselmagazine.com/articles/3837/camelin a-meal-approved-for-feedlot-cattle

[6] A. Schuster and W. Friedt, "Glucosinolate Content and Composition as Parameters of Quality of Camelina Seed," Industrial Crops and Products, Vol. 7, No. 2-3, 1998, pp. 297-302. http://dx.doi.org/10.1016/S0926-6690(97)00061-7

[7] M. E. Daxenbichler, G. F. Spencer, D. G. Carlson, G. B. 
Rose, A. M. Brinker and R. G. Powell, "Glucosinolate Composition of Seeds from 297 Species of Wild Plants," Phytochemistry, Vol. 30, No. 8, 1991, pp. 2623-2638. http://dx.doi.org/10.1016/0031-9422(91)85112-D

[8] R. Russo and R. Reggiani, "Antinutritive Compounds in Twelve Camelina sativa Genotypes,” American Journal of Plant Sciences, Vol. 3, No. 10, 2012, pp. 1408-1412. http://dx.doi.org/10.4236/ajps.2012.310170

[9] G. Séguin-Swartz, J. A. Nettleton, C. Sauder, S. I. Warwick and R. K. Gugel, "Hybridization between Camelina sativa (L.) Crantz (False Flax) and North American Camelina Species,” Plant Breeding, Vol. 132, No. 4, 2013, pp. 390-396. 